\title{
A PROSPECTIVE STUDY ON THE OUTCOMES FOLLOWING LCP CONDYLAR PLATE FIXATION IN AO TYPE C DISTAL FEMORAL FRACTURES
}

\author{
Vikas Singhal ${ }^{1}$, Ashish Gohiya ${ }^{2}$ \\ ${ }^{1}$ Consultant Orthopaedic Surgeon, Department of Orthopaedics, Singhal Orthocare, Gwalior. \\ 2 Professor, Department of Orthopaedics, Gandhi Medical College, Bhopal.
}

\begin{abstract}
Fractures of the distal third of the femur especially AO type C are a treatment challenge despite new fixation options. Fixed angle locking plates have become the most commonly used device for this indication replacing intramedullary nails, blade plates and condylar screws. In this study we analyze the functional outcome of open reduction and rigid internal fixation using LCP condylar plate in AO type C distal femoral fractures.

METHODOLOGY: We studied the results of LCP Condylar plate fixation in 30 patients with AO type C distal femoral fractures over a period of 22 months at our institution. Functional outcome is measured with Neer`s criteria.

RESULTS: Out of 30 patients, 11 patients (36.7\%) achieved excellent and 11 patients (36.7\%) achieved satisfactory outcome. 3 patients $(10 \%)$ achieved unsatisfactory and 5 patients $(16.6 \%)$ achieved poor outcome. We found that, open fractures, articular comminution, infection, lack of rigid internal fixation and malalignment are the major culprits for a poor functional outcome.

CONCLUSION: The LCP condylar plate is an acceptable surgical option for treatment of AO type C distal femoral fractures by achieving early mobility due to primary stability of the construct.
\end{abstract}

KEYWORDS: Distal Femur Fracture, Supracondylar Femur Fracture, LCP Condylar Plate.

HOW TO CITE THIS ARTICLE: Vikas Singhal, Ashish Gohiya. "A Prospective Study on the Outcomes following LCP Condylar Plate Fixation in AO Type C Distal Femoral Fractures". Journal of Evolution of Medical and Dental Sciences 2015; Vol. 4, Issue 93, November 19; Page: 15857-15862, DOI: 10.14260/jemds/2015/2301

INTRODUCTION: The incidence of distal femoral fractures is $4-7 \%$ of all femur fractures.[1,2] There is a bimodal distribution, with young patients with high energy trauma and elderly patients with low-energy falls. Approximately $85 \%$ of these fractures occur in patients over fifty years old.[3] The incidence of supracondylar fracture after total knee arthroplasty is approximately $1 \%$.

Management of distal femur fractures has developed from conservative treatment always to early fixation and mobilization always. This sea of change has been caused by the improvement of diagnostics, surgical modalities and change in philosophies of fracture care. Operative treatment of distal femur fractures was revolutionized in the 1970s with the advent of $\mathrm{AO}$ implants, instruments and techniques.

Available implants for fixation of these fractures are Fixed angle blade plate, condylar buttress plate, dynamic condylar screw (DCS), Cancellous screws, Locking condylar buttress plate, Retrograde interlock nail and antegrade interlocking nail. ${ }^{[4-8]}$

The use of fixed angle devices such as condylar blade plate and DCS require a certain amount of bone stock present, which limits their use in some fracture types. This lead to development of condylar buttress plates for comminuted fractures. However with standard buttress plating, these fractures often fall into a varus deformity.

Financial or Other, Competing Interest: None.

Submission 31-10-2015, Peer Review 02-11-2015,

Acceptance 09-11-2015, Published 18-11-2015.

Corresponding Author:

Dr. Vikas Singhal,

Flat No. 203, Shraddha Residency,

B-Block,

Near Gwalior Glory School,

Harishankarpuram, Gwalior-474005,

Madhya Pradesh.

E-mail: vikasortho16@gmail.com

DOI:10.14260/jemds/2015/2301.
Biomechanical studies revealed that gross loosening of the standard condylar buttress plate and DCS occurred because of toggle at the screw plate interface.

Different modalities have been used to prevent failure in the distal femoral fragment, including double plating. ${ }^{[9]}$ and a "Push-screw" as described by Simonian et al.[10] To address these issues, locking condylar plate was designed. A locking plate decreases screw plate toggle and motion at the bone screw interface and provides more rigid fixation.

Higgins et al in their study comparing strength of fixed angle blade plate to that of locking condylar buttress plate and mentioned the later to be significantly stronger construct.[11] Hence the recent introduction of fixed-angle screw plate technology may present surgeons with a more accommodating alternative to the blade plate, without sacrificing fixation.

It furthers the concept of fixed angle devices by allowing locking of multiple screws in different planes, a feature not available with the condylar blade plate or the DCS. The locking condylar plate works particularly well for fractures that are otherwise difficult to treat, including periprosthetic fractures, communited fractures and fractures in osteoporotic bone. When combine with minimally invasive surgical techniques, locked plating may cause less iatrogenic tissue damage when compared with conventional plating.[12,13]

One concern with locking plate constructs is that the high stiffness achieved may limit the amount of callus, resulting in delayed healing or nonunion.[14,15] For communited fractures treated with a bridging technique, peripheral callus is necessary for fracture healing.

The purpose of this study was to evaluate the results \& final outcome of LCP condylar plate as a treatment modality for AO type $\mathrm{C}$ distal femoral fractures. Functional results were evaluated with regard to pain, range of motion of knee, limb length discrepancy, any persisting deformity, presence and absence of early and late complications etc. Attempts were also made to identify specific causes directly related to the bad results in this series. 
It is hoped that the results of this study will be of help in more careful selection of patients and implants, and thereby avoiding a large number of complications which are actually the results of inadequate preoperative planning and case selection.

METHODOLOGY: A prospective study of 30 patients, with AO type $\mathrm{C}$ distal femoral fractures treated surgically with LCP condylar plate, was carried out at Department of Orthopaedics and Traumatology, Gandhi Medical College and Hamidia Hospital, Bhopal. As per the practical utility AO/OTA classification is the most preferred.[16] So for our study we have used $\mathrm{AO}$ classification and only include $\mathrm{AO}$ type $\mathrm{C}$ distal femoral fractures for our study.

Inclusion and Exclusion Criteria: Patients of both sexes above 16 years, Closed and Open fractures, and AO Type C fractures were included in the study. Pathological fractures and AO type A \& B fractures were excluded.

Initial Treatment and Pre-operative Preparation: Initial resuscitation and stabilization of the patients were done. In terms of the management of open fractures, initial irrigation, debridement, intravenous antibiotic, upper tibial pin traction or external fixator application and delayed wound closures were done routinely. From the initial radiographs, all fractures were classified according to AO classification.

Operative Management: We had applied LCP Condylar plate in either an open, or a minimally invasive manner. When we have inserted it in an open manner, a lateral parapatellar approach or its extension Swashbuckler approach was used.[17] In the treatment of AO type C distal femoral fractures, we have first reconstructed the distal femoral articular block. After analyzing the fragments, temporary reduction was attained with $\mathrm{K}$ wire. Definitive fixation was done LCP condylar plate. Then we have gently moved the knee through a full range of motion. We have examined the knee for any ligamentous instability. We have irrigated all wounds copiously. We have closed the iliotibial tract using absorbable sutures. With the use of suction drains we have closed the skin and subcutaneous tissue in the routine manner.

Post-operative after treatment: Post operatively the limb was kept in Bohler Braun splint to prevent contracture of the quadriceps. Isometric quadriceps exercise started by third day of surgery in all patients. At the same time non-weight bearing gait training started with the help of crutches or walker. Touchdown partial weight bearing started at on an average of $8^{\text {th }}$ weeks, until there were radiographic signs of callus formation. Full weight bearing started only when there were clinical and radiological signs of union.

Follow up Protocol: These patients were clinically and radiologically examined and followed up from the time of their OPD attendance/admission, their stay in the hospital to the subsequent follow up, at every four weeks interval. A record of history and treatment given and the results of treatment for each patient were maintained in a follow up proforma. The functional and radiographic results were recorded according to Neer's criteria. Functional grading was made depending on pain, walking capacity, joint movement and work capacity. Radiological grading was made based on varus or valgus deformity, shortening, signs of osteoarthritis and union of fracture. At the time of final follow up, all these patients were given a final over-all rating using the system of Neer et al.[18]

Outcome can be Excellent (More than 85 points), satisfactory (70-85 points); unsatisfactory (55-69 points); and poor (Less than 55 points). We considered a fracture united if there were no pain on palpation or attempted motion, no increase in warmth at the fracture site, no discomfort on full weight bearing and serial roentgenograms demonstrated bone trabaculae crossing the fracture site.

Case Example: A 41 years old male was involved in a motor vehicle accident and sustained an open A0 type 33C3 fracture of the left distal femur (Fig. 1). Initial surgical management included wound debridement and spanning external fixator application. Definitive delayed open reduction and internal fixation with LCP condylar plate was performed for his left distal femur (Fig. 2). He was discharged well with wheelchair ambulation and physiotherapy on an outpatient basis. At six months, he was fully bearing weight and had good range of motion and radiographs revealed complete fracture healing. (Fig. 3, 4)
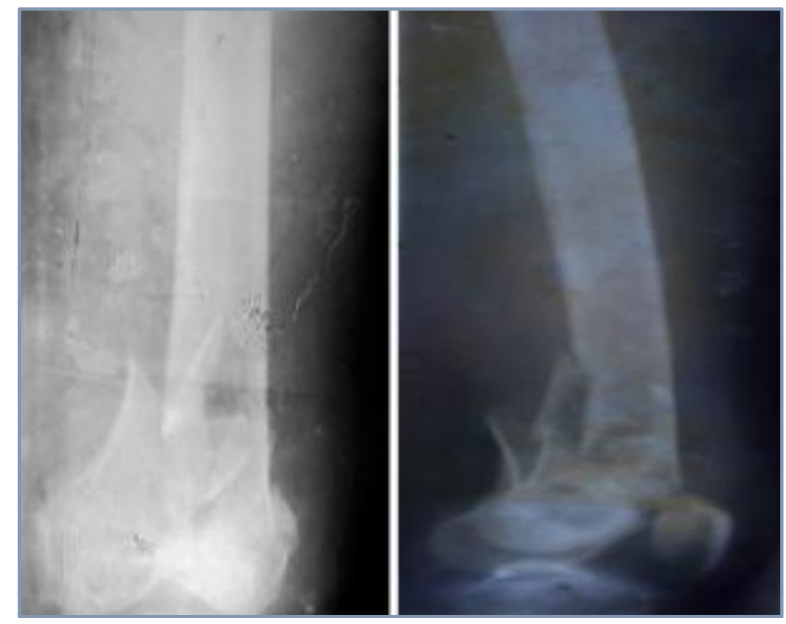

Fig. 1: Preoperative radiograph
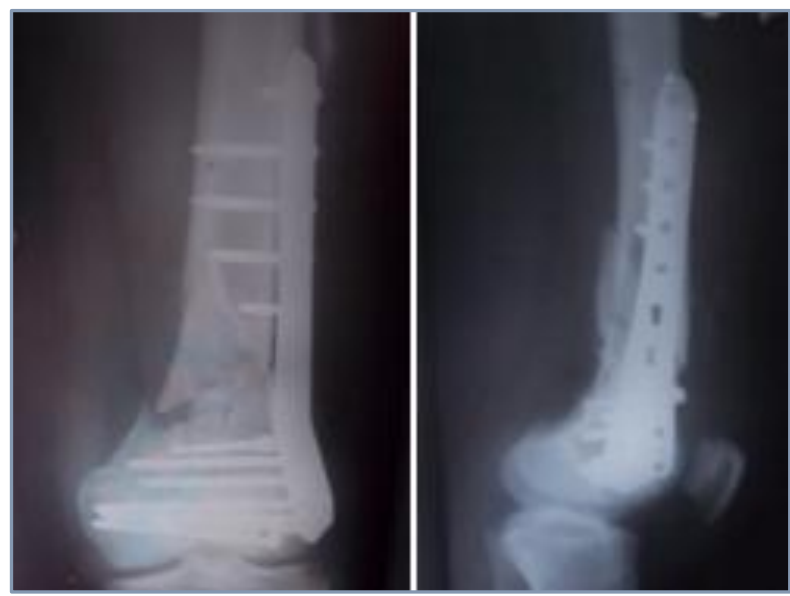

Fig. 2: Postoperative radiograph 


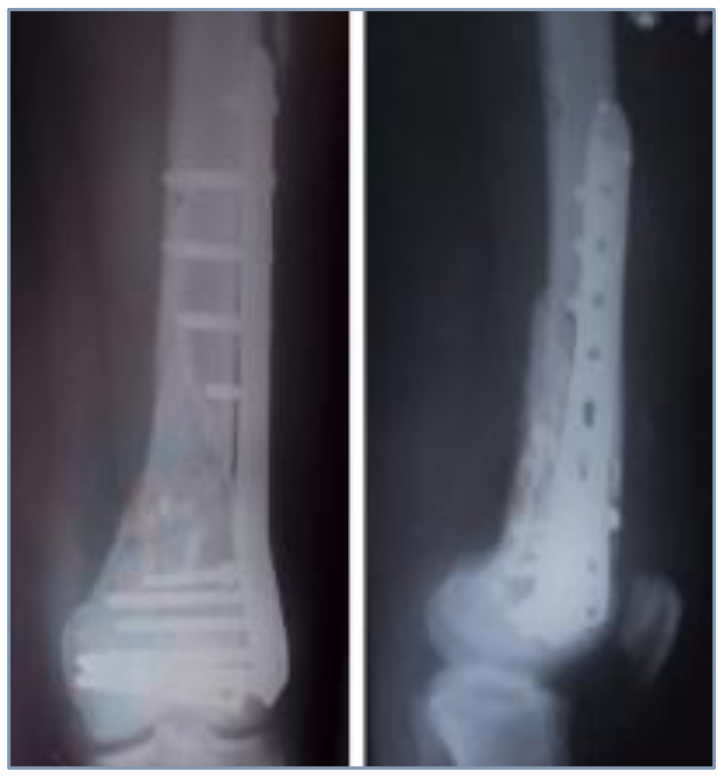

Fig. 3: Radiograph at 6 months

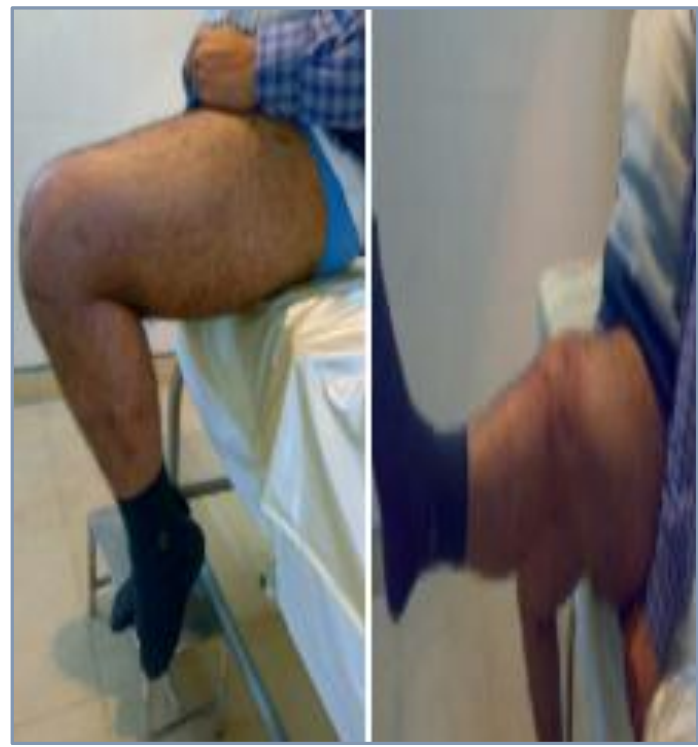

Fig. 4: Knee range of motion at 6 months

RESULTS: The present study comprised of analysis of 30 cases of AO type $\mathrm{C}$ distal femoral fractures. The case study was spanned over a period of 22 months. The period of follow up was from a minimum of 6 months to a maximum of 20 months, the average length being 9 months. There were no neurovascular injuries in our series and no deaths.

Patient Population: Study comprises total of 30 patients, in the age range of 18 to 65 years. (Average age=38.06 yrs.). 25 patients were men with the age range of 18-65 yrs. (Average age $=35.52$ yrs.) while 5 patients were women with the age range of 25 to 63 yrs. (Average age $=50.8$ yrs.)

\begin{tabular}{|c|c|c|}
\hline Age Group (In years) & Male & Female \\
\hline $10-20$ & 3 & 0 \\
\hline $21-30$ & 7 & 1 \\
\hline $31-40$ & 8 & 0 \\
\hline $41-50$ & 6 & 1 \\
\hline $51-60$ & 0 & 1 \\
\hline $61-70$ & 1 & 2 \\
\hline Total & $\mathbf{2 5}$ & $\mathbf{5}$ \\
\hline Table 1: Age and Sex distribution of patients \\
\hline
\end{tabular}

Fracture Type: Left femur was object in 11 cases (36.7\%) while right femur was object in 19 cases (63.3\%). 15 fractures were closed (50\%) while 15 fractures were open (50\%) with Gustilo grade I in three, Gustilo grade II in six and Gustilo grade III in six. Among 30 fractures 2 were of type C1, 8 were of type $\mathrm{C} 2$, and 18 were of type C3. Out of 25 fractures in males 1 was C1, 6 were C2 and 18 were C3. Out of 5 fractures in females 1 was C1, 2 were C2 and 2 were C3. Average age for $\mathrm{C} 1$ fractures were 27.5 years, for $\mathrm{C} 2$ fractures 46 years and for $\mathrm{C} 3$ fractures it were 36 years.

Associated Injuries: They were present in 10 cases (33.3\%). 4 cases were presented with ipsilateral fracture both bone leg and 3 patients were presented with fracture patella and 2 patients were presented with fracture proximal tibia. Other associated injuries were ipsilateral fracture calcaneum, fracture of Lower end radius ipsilateral, humerus fracture, bimalleolar fracture of ankle ipsilateral.

Mode of Injury: Road traffic accidents (66.67\%) were the commonest mode of injury followed by falls (33.34\%).

Injury Operation Interval: 17 cases was operated between 3 to 7 days while 12 cases was operated between 8 to 14 days. One case was operated after 18 days of injury.

Duration lag between the time of injury and the definitive treatment ranged from 3 days to 18 days, average being 7.8 days.

Time to Union: It was ranged from 12 to 30 weeks (Average -18 weeks). Percentage of cases showing full union was $94 \%$ except two case $6 \%$ which showed non-union.

The time to full weight Bearing: It was ranged from 12-30 weeks average being 19 weeks. Majority of patients (14) was able to bear weight after 20 weeks and above.

Knee Movement: The time of final follow up more than half of the patients was having range of movement of more than $90^{\circ}$ (Average range of knee motion being $96.83^{\circ}$ ).

\begin{tabular}{|c|c|c|c|}
\hline $\begin{array}{c}\text { Type of } \\
\text { fracture }\end{array}$ & $\begin{array}{c}\text { No. of } \\
\text { fractures }\end{array}$ & $\begin{array}{c}\text { Average Time } \\
\text { of union } \\
\text { (in weeks) }\end{array}$ & $\begin{array}{c}\text { Average } \\
\text { range of } \\
\text { movement at } \\
\text { knee }\end{array}$ \\
\hline Closed & 15 & 15.46 & $112.33^{0}$ \\
\hline Open & 15 & 20.46 & $81.33^{0}$ \\
\hline $\begin{array}{c}\text { Table 2: Relation between Type of Fracture (Open/Closed) } \\
\text { and Average time of union (in weeks) and average range } \\
\text { of movement at knee }\end{array}$ \\
\hline \multicolumn{4}{|c|}{}
\end{tabular}

Final Outcome: At the final follow up, final functional outcome has been measured with the help of Neer`s criteria. Out of 30 patients, 11 patients (36.7\%) achieved excellent and 11 patients $(36.7 \%)$ achieved satisfactory outcome. 3 patients (10\%) achieved unsatisfactory and 5 patients $(16.6 \%)$ achieved poor outcome. 


\begin{tabular}{|c|c|c|c|c|c|}
\hline $\begin{array}{c}\text { Fracture } \\
\text { type }\end{array}$ & $\begin{array}{c}\text { Associated } \\
\text { Injuries }\end{array}$ & $\mathbf{A}^{*}$ & $\mathbf{B} \dagger$ & $\mathbf{C} \neq$ & $\mathbf{D} \S$ \\
\hline \multirow{2}{*}{$\mathrm{C} 1$} & Present & 0 & 0 & 0 & 0 \\
\cline { 2 - 6 } & Absent & 2 & 0 & 0 & 0 \\
\hline \multirow{2}{*}{$\mathrm{C} 2$} & Present & 0 & 0 & 0 & 1 \\
\cline { 2 - 6 } & Absent & 5 & 2 & 0 & 0 \\
\hline \multirow{2}{*}{$\mathrm{C} 3$} & Present & 1 & 5 & 0 & 3 \\
\cline { 2 - 6 } & Absent & 3 & 4 & 3 & 1 \\
\hline \multirow{2}{*}{ TOTAL } & & $\begin{array}{c}\mathbf{1 1} \\
\mathbf{( 3 6 . 6 \% )}\end{array}$ & $\begin{array}{c}\mathbf{1 1} \\
\mathbf{( 3 6 . 6 \% )}\end{array}$ & $\begin{array}{c}\mathbf{3} \\
(\mathbf{1 0 \% )}\end{array}$ & $\begin{array}{c}\mathbf{5} \\
\mathbf{( 1 6 . 6 )}\end{array}$ \\
\hline
\end{tabular}

Table 3: Correlation between Fracture type, Associated injuries and Final functional outcome

A* - Excellent (>85 points), B $\uparrow$ - Satisfactory (70- 85 points), C - Unsatisfactory (55-69 points), D§ - Poor $(<55$ points)

\begin{tabular}{|c|c|c|c|c|c|}
\hline $\begin{array}{c}\text { Fracture } \\
\text { type }\end{array}$ & $\begin{array}{c}\text { Open/ } \\
\text { Closed }\end{array}$ & $\mathbf{A}^{*}$ & $\mathbf{B} \dagger$ & $\mathbf{C} \neq$ & $\mathrm{D} \S$ \\
\hline \multirow{2}{*}{$\mathrm{C} 1$} & Open & 0 & 0 & 0 & 0 \\
\cline { 2 - 6 } & Closed & 2 & 0 & 0 & 0 \\
\hline \multirow{2}{*}{$\mathrm{C} 2$} & Open & 1 & 0 & 0 & 1 \\
\cline { 2 - 6 } & Closed & 4 & 2 & 0 & 0 \\
\hline \multirow{2}{*}{$\mathrm{C} 3$} & Open & 0 & 7 & 2 & 4 \\
\cline { 2 - 6 } & Closed & 4 & 2 & 1 & 0 \\
\hline \multirow{2}{*}{ TOTAL } & & $\begin{array}{c}\mathbf{1 1} \\
(\mathbf{3 6 . 6 \% )}\end{array}$ & $\begin{array}{c}\mathbf{1 1} \\
\mathbf{( 3 6 . 6 \% )}\end{array}$ & $\begin{array}{c}\mathbf{3} \\
(\mathbf{1 0} \%)\end{array}$ & $\begin{array}{c}\mathbf{5} \\
\mathbf{1 6 . 6 )}\end{array}$ \\
\hline \multicolumn{5}{|c}{ Table 4: Correlation of fracture type, } \\
Compounding and final functional out come \\
\hline
\end{tabular}

$A^{*}$ - Excellent (>85 points), B $\dagger$ - Satisfactory (70- 85 points), C - Unsatisfactory (55-69 points), D§ - Poor ( $<55$ points).

Complications: On follow up, 4 patients developed infection and 4 patients developed delayed union. Other complications encountered in this study included plate impingement $(n=2)$, non-union $(n=2)$, malalignment $(n=5)$.

DISCUSSION: Fractures in the distal femur have posed considerable therapeutic challenges throughout the history of fracture treatment.[18,19,20] Most of these surgical failures were due to inadequate fixation of the fracture fragments. ${ }^{[21]}$ The prognostic factors for supracondylar fracture included age, intra-articular involvement, methods of treatment, timing of joint motion, etc.[18,22]

In this study most of the patients were in the age group between 18-45 yrs. The average age was 38.06 yrs., which is quite comparable with average age of series of Weight et al.[23] in which average age was 44 yrs. and of Yeap et al.[24] in which average age was 44 yrs. But it is in contrast with Markmiller et al.[25] where average age was over 55 years of age. All the above studies include all types of distal femoral fractures but we have included only AO type C fractures.

This shows that high velocity trauma is more commonly seen in younger patients and the intensity of fractures has been increased. The present study does not show a biphasic age distribution of the patient population as is usually seen in studies.[26] This is a reflection of the mechanism of injury which was high energy trauma like RTA in $66.67 \%$ of patients most of whom were younger. This correlates well with the high degree of associated trauma seen and with the high incidence of open fracture ( $50 \%$ of the patients).

Male patients dominated the series because of the nature of their outdoor activities. A high male to female ratio 5:1 was found. This is in contrast to Stewart. ${ }^{[20]}$ who found an equal sex distribution in his series and in the series of Handolin L. et al.[27] in which more than half of the patients were women.
In our series, road traffic accidents, accounted for the highest incidence of these injuries $(66.67 \%)$, followed by fall (33.4\%), which is in agreement with the recent reports which show that increased incidence of vehicular accidents and resultant high velocity trauma are probably due to modernization and mechanization of life. Similar high percentages of these injuries due to RTA were found in the study of Saw A. et al. ${ }^{[28]}$ in which it was $92 \%, \& 63 \%$ in the series of Yeap et al.[24]

In this study ipsilateral fracture both bone leg was the commonest associated injury seen in four patients $(13.33 \%)$. Borgen and Sprague.[29] had also observed fractures of the ipsilateral lower limb as the commonest associated injury. The percentage of open fractures treated with LCP Condylar plate in this series was $50 \%$, out of which $20 \%$ are of Gustilo grade II \& $20 \%$ are of grade III \& $10 \%$ are of grade I. It is equivalent to the percentage of open fractures of $46.7 \%$ in the study of Frankhauser.[30] \& $54.3 \%$ in the study of Vallier et al.[31]

In our series duration lag between the time of injury and the definitive treatment ranged from 3 days to 18 days, average being 7.8 days which is comparable to the study of Yeap et al.[24] In their study average number of days from injury to surgery was 9.9 days with a range of 4 to 19 days.

Vallier et al.[31] reported a series of 46 patients with type $\mathrm{A} 3$ and $\mathrm{C}$ fractures treated with LCP Condylar plate with $84.78 \%$ rate of union and failure of 6 cases. Results of this series of are quite comparable with present study $94 \%$ union and only two cases of nonunion. In the series of Vallier et al.[31] six patients required bone grafting in contrast to the present series in which such a high rate of union obtained with only one case of primary bone grafting. However 4 patients undergo bone marrow infiltration for delayed union in our series.

No studies till date have mentioned the use of bone marrow infiltration for union. In the series of Yeap et al.[24] rate of union were $90.9 \%$ and 2 patients out of 11 patients undergo secondary bone grafting.

In our series average time to union was 18 weeks which is quite comparable with other studies. Yeap et al.[24] got same average time of union while Frankhauser.[30] has got average time of union of 12 weeks. It is in contrast of the study performed by Wong et al.[32] They found average time of union 30 weeks. Previous studies using lateral screw and plate fixation report similar times to healing, but $25-35 \%$ of these patients underwent bone grafting acutely with reports of delayed union and non-unions.[19,33] In our series we found that average time of union is more in open fractures as compared to closed fracture.

In our series we found average range of motion of knee joint 96.83 degrees (Less in open fractures than closed fractures) which is comparable to other studies.

We have evaluated the result based on Neers criteria. Based on this criterion we found 36\% (11 patients) excellent result, $36 \%$ (11 patients) satisfactory result, $17 \%$ (5 patients) poor result \& $10 \%$ (3 patients) unsatisfactory result. In a study by Mize et al.[21] there was a $21 \%$ poor result which is comparable with the present study. When these cases are closely analysed, many factors are found to be responsible for the bad results. Major contributing factors are:

- Open injuries and associated injuries are more prone for bad results.

- Higher the comminution or grade of fracture leads to more chances of poor results. 
- Delay in starting active exercises also contributed to the bad results.

In our series infection rate was $13.33 \%$ which is higher than other studies. Infection rate of $3 \%$ was found by Kregor et al.[7] \& Schutz et al..[34] Higher infection rate in our study may be due to higher number of patient with compound injury \& unhygienic condition of poor patients. But all patients were responded to antibiotic. Due to infection, these patients have taken more time to unite as compared to other patients.

In our series there is one complication which is yet not reported. Two patients have pain with knee flexion. Their X ray shows that anterior part of plate was impinging to the patella. After removal of plate, pain due to knee flexion subsided \& also range of flexion has been increased. On close look this was due to defective shape of LCP condylar plate available at our institution.

Two common confounding variables in the present study were the existence of ligamentous injuries and the presence of pre existing arthritic condition. These factors contributed to the relatively low number of excellent results in this study. Other limitation of this study is that this is performed in a government medical college in which most of the patients were of low socioeconomic status. Despite repeated instructions on follow up some patients was not following the advices leading to more number of poor results.

CONCLUSION: The LCP condylar plate is a single beam construct where the strength of its fixation is equal to the sum of all screw-bone interfaces rather than a single screw's axial stiffness and pullout resistance in unlocked plates.

The LCP condylar plate is a further development from the LISS (Less invasive stabilization system) which was introduced in the mid to late 1990 's. ${ }^{[35,36]}$ The main difference between the LCP condylar plate and the LISS is that the LISS utilises an outrigger device for shaft holes, functioning essentially as a locking guide jig, which is attached to the distal part of the plate and guides the placement of the proximal locking screws. The shaft holes on the LCP condylar plate are oval allowing for the options of a compression screw or a locking screw. This leads to a more precise placement of the plate, as it is able to be compressed more closely to the bone.

As the baby boomer population continues to age and high-energy mechanisms of injury continue to exist, distal femur fractures will continue to increase in incidence and complexity. The challenges faced in treating these fractures continue to include a short articular segment, bone loss in open fractures, and osteoporotic bone. As implants and techniques have evolved, the same treatment goals have remained; these include restoration of limb alignment, anatomic articular reduction, and early knee motion. Although the role of locking plates has continued to expand over recent years, clinical studies have yet to demonstrate a significant improvement in outcomes with their use.

Hence it is concluded that supracondylar/distal femoral fractures specially AO type $C$ can be effectively treated by LCP Condylar plate. It leads to rapid bone healing despite of severe comminution, avoiding the need for bone grafting because of less soft tissue dissection and periosteal stripping and non-interference with facture hematoma. LCP condylar plate fixation is very useful for fixation of type C3 fracture.
However, accurate positioning and fixation are required to produce satisfactory results.

\section{REFERENCES:}

1. Arneson TJ, Melton LJ, Lewallen DG, et al. Epidemiology of diaphyseal and distal femoral fractures in Rochester, Minnesota, 1965-1984. Clin Orthop Relat Res 1988; 234:188-194.

2. Martinet 0 , Cordey J, Harder Y, Maier A, Buhler M, Barraud GE. The epidemiology of fractures of the distal femur. Injury. 2000; 31(suppl 3):C62-C63.

3. Shewring DJ, Meggitt BF. Fractures of the distal femur treated with the AO dynamic condylar screw. J Bone Joint Surg Br 1992; 74:122-125.

4. Harder Y, Martinet O, Barraud GE, et al: The mechanics of internal fixation of fractures of the distal femur: a comparison of the condylar screw (CS) with the condylar plate (CP), Injury 30:A31, 1999.

5. Kregor PJ, Stannard J, Zlowodzki M, Cole PA, Alonso J. Distal femoral fracture fixation utilizing the Less Invasive Stabilization System (L.I.S.S.): the technique and early results. Injury. 2001; 32 Suppl 3:SC32-47.

6. Marek DJ, Cole PA, Kregor PJ. Operative treatment of acute distal femur fractures: systematic review of 2 comparative studies and 45 case series (1989 to 2005). J Orthop Trauma.2006; 20(5):366- 371. Surg. 1998; 118(12):92-95.

7. Kregor PJ, Stannard JA, Zlowodzki M, Cole PA. Treatment of distal femur fractures using the less invasive stabilization system: surgical experience and early clinical results in 103 fractures. J Orthop Trauma 2004; 18:509. 20.

8. Thomas F. Higgins, Gavin Pittman, Jerod Hines, Kent N. Bachus, Biomechanical Analysis of Distal Femur Fracture Fixation: Fixed- Angle Screw-Plate Construct Versus Condylar Blade Plate J Orthop Trauma 2007;21:43-46.

9. Sanders R, Swiontkowski M, Rosen H, et al. Double-plating of comminuted, unstable fractures of the distal part of the femur. J Bone Joint Surg Am. 1991; 73:341-346.

10. Simonian PT, Thompson GJ, Emley W, et al. Angulated screw placement in the lateral condylar buttress plate for supracondylar femoral fractures. Injury. 1998; 29:101104.

11. Higgins TF, Pittman G, Hines J, Bachus KN. Biomechanical analysis of distal femur fracture fixation: fixed-angle screwplate construct versus condylar blade plate. J Orthop Trauma. 2007; 21(1):43-46.

12. Kubiak EN, Fulkerson E, Strauss E, Egol KA. The evolution of locked plates. J Bone Joint Surg Am.2006; 88 (Suppl 4):189-200. Dec.

13. Egol KA, Kubiak EN, Fulkerson E, Kummer FJ, Koval KJ. Biomechanics of locked plates and screws. J Orthop Trauma. 2004; 18 (8):488-93. Sep.

14. Henderson CE, Bottlang M, Marsh JL, Fitzpatrick DC, Madey SM. Does locked plating of periprosthetic supracondylar femur fractures promote bone healing by callus formation? Two cases with opposite outcomes. Iowa Orthop J. 2008; 28:73-6. 
15. Lujan T, Henderson CE, Madey SM, Fitzpatrick DC, Marsh JL, Bottlang M. Locked plating of distal femur fractures leads to inconsistent and asymmetri cal callus formation. JOT. In press.

16. Fracture and dislocation compendium. Orthopaedic Trauma Association Committee for Coding and Classification. JOrthop Trauma. 1996; 10(suppl 1: v-IX):1154.

17. Starr AJ, Jones AL, Reinert CM: The "Swashbuckler": A modified anterior approach for fractures of the distal femur. J Orthop Trauma 13: 138-140, 1999.

18. Neer C. S., Grantham S. A. \& Shelton M. L.: Supracondylar fracture of the adult femur. J. Bone Joint Surg. 1967, Vol. 49 A: 591.

19. Shatzker J, Lambert DC. Supracondylar fractures of the femur. Clin Orthop 1979; 138: 77-83.

20. Stewart MJ, Sisk TD, Wallace SL. Fractures of the distal third of the femur. J Bone Joint Surg 1966; 48A: 784-807.

21. Mize RD, Bucholz RW, Grogan DP. Surgical treatment of displaced comminuted fractures of the distal end of the femur. J Bone Joint Surg 1982; 64A: 871-879.

22. Moore TJ, Watson T, Green SA, Garland DE, Chandler RW. Complications of surgically treated supracondylar fractures of the femur. J Trauma 1987; 27: 402-406.

23. Weight M, Collinge C. Early Results of the Less Invasive Stabilization System for Mechanically Unstable Fractures of the Distal Femur (A0/OTA Types A2, A3, C2, and C3). J Orthop Trauma 2004; 18(8): 503-8.

24. EJ Yeap, AS Deepak: Distal Femoral Compression plate fixation in Distal femoral fractures: Early Results:Malaysian Orthopaedic Journal 2007 Vol 1 No 1.

25. Markmiller M, Konrad G, Sudkamp N. Femur-LISS and Distal Femoral Nail for Fixation of Distal Femoral Fractures. Clin Orthop 2004; 426: 252-7.

26. Bell KM, Johnstone AJ, Court-Brown CM, Hughes SPF. Primary knee arthroplasty for distal femoral fractures in elderly patients. J Bone Joint Surg 1992; 74B: 400-402.
27. Handolin L., Panarinen J: Retrograde intramedullary nailing insupracondylar femoral fractures - The Toolo Hospital Experience: SOT 1/2002, vol. 5, 46-51.

28. Saw A., Lau C.P.: Supracondylar nailing for difficult distal femur fractures: J. Orthop Surg. 2003: (11) 2: 141-147.

29. Borgen D., Sprague B.L.; Treatment of distal femoral fractures with early weight bearing. Clinical Orthopadics No. III, September 1975.

30. Fankhauser F, Gruber G, Schippinger G, et al. MinimalInvasive Treatment of Distal Femoral Fractures with the LISS (Less Invasive Stabilization System): A Prospective Study of 30 Fractures with a Follow Up of 20 Months. Acta Orthop Scand 2004; 75(1): 56-60.

31. Vallier HA, Hennessey TA, Sontich JK, Patterson BM. Failure of LCP condylar plate fixation in the distal part of the femur. A report of six cases. J Bone Joint Surg Am. 2006; 88(4):846-853.

32. Wong MK, Leung F, Chow SP. Treatment of Distal Femoral Fractures in the Elderly Using a Less-Invasive Plating Technique. Int Orthop 2005; 29: 117-20.

33. Giles J. B., Delee J. C. Heckman J. D. \& Keever J. E.: Supracondylar - intercondylar fractures of the femur treated with a supracondylar plate and lag screw: J. Bone Joint Surg., 1982; Vol. 64A: 864.

34. Schutz M, Muller M, Regazzoni $P$, et al. Use of the Less Invasive Stabilization System (LISS) in patients with distal femoral (A033) fractures: a prospective multicenter study. Arch Orthop Trauma Surg 2005; 125(2): 102-8.

35. Schandelmaier P, Partenheimer A, Koenemann B, Grun OA, Krettek C. Distal Femoral Fractures and LISS Stabilization. Injury 2001; 32: SC 55-63.

36. Frigg R, Appenzeller A, Christensen R, Frenk A, Gilbert S, Schavan R. The development of the distal femur Less Invasive Stabilization System (LISS). Injury 2001; 32: SC 24-31. 